\title{
Characterization of the Pharmacokinetics of Samidorphan in Healthy Volunteers: Absolute Bioavailability and the Effect of Food and Age
}

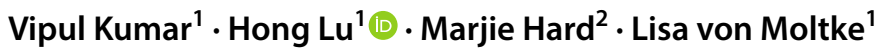

Published online: 29 August 2019

(c) The Author(s) 2019

\begin{abstract}
Background and Objectives Samidorphan (SAM) is a novel $\mu$-opioid receptor antagonist. We report clinical pharmacokinetic (PK) properties of SAM following different routes of administration, and the effects of food and age on the PK of SAM following oral administration in healthy volunteers.

Methods An open-label, fixed-sequence study (study 1, N=10) examined the PK parameters following intravenous, sublingual, and oral exposure to SAM to determine absolute bioavailability. A double-blind, placebo-controlled study (study 2, $N=45$ ) compared the PK in participants aged $18-40$ years (cohort $1, n=30$ ) and $\geq 65$ years (cohort $2, n=15$ ) who received a single oral dose of SAM $10 \mathrm{mg}$ under fed (cohort 1 only) or fasted conditions.

Results In study 1, intravenous SAM had a plasma clearance of $33.7 \mathrm{~L} / \mathrm{h}$, volume of distribution of $341 \mathrm{~L}$, and elimination half-life of 7-8 h. SAM was well-absorbed following sublingual or oral administration and reached peak concentrations $\left(C_{\max }\right)$ within $2 \mathrm{~h}$, with absolute bioavailability of $71 \%$ (sublingual) and 69\% (oral). In study 2, concentration-time profiles were similar under fed and fasted conditions (cohort 1) and for young and elderly participants from both cohorts; $90 \%$ confidence intervals for the geometric least squares mean ratios for $C_{\max }$ and area under the concentration-time curve from time zero extrapolated to infinity indicated equivalence.

Conclusions SAM has high bioavailability that is comparable following sublingual and oral administration and is not subject to extensive first-pass metabolism. The PK of orally administered SAM are not affected by food or age.
\end{abstract}

\section{Key Points}

When taken sublingually or orally, samidorphan (SAM) has high bioavailability.

When taken orally, the pharmacokinetics of SAM are not affected by food or age.
Vipul Kumar and Hong Lu contributed equally to the preparation of this manuscript.

Lisa von Moltke

Lisa.vonMoltke@alkermes.com

1 Alkermes Inc, 852 Winter Street, Waltham, MA 02451, USA

2 Moderna Therapeutics, Cambridge, MA, USA

\section{Introduction}

Samidorphan (3-carboxamido-4-hydroxynaltrexone; ALKS 33; SAM), a naltrexone derivative, is a new chemical entity that binds with high specificity and selectivity to $\mu-, \delta-$, and $\kappa$-opioid receptors [1-4]. SAM acts primarily as a potent $\mu$-opioid receptor antagonist, blocking the miotic and 'drugliking' effects of the $\mu$-opioid receptor agonists buprenorphine and remifentanil following sublingual and oral administration, respectively [5-7]. Oral administration of SAM has been associated with rapid and sustained blockade of opioid agonist challenge, with physiological and subjective effects blocked within 15 min of dosing and persisting for up to $48 \mathrm{~h}$ postdose [7]. The use of SAM monotherapy in binge-eating and alcohol dependence disorders has also been investigated [8, 9]. SAM is currently under clinical development as part of two combination therapies: with buprenorphine (buprenorphine/SAM; ALKS 5461) as a sublingual therapy for major depressive disorder [5, 6] and with olanzapine (olanzapine/SAM; ALKS 3831) as an oral therapy for schizophrenia [10, 11]. 
The pharmacokinetic (PK) profile of SAM after oral administration was characterized in a first-in-human study [1]. SAM was rapidly absorbed, with a time to maximum concentration $\left(t_{\max }\right)$ of $1 \mathrm{~h}$ and an increasing area under the curve (AUC) with increasing dose. The half-life of SAM after oral administration was approximately 7-9 h. With repeated daily oral dosing, steady state was approached after 5-7 days, with low accumulation (accumulation ratios $<1.65$ ) [1]. SAM was well tolerated after single oral doses of up to $55.7 \mathrm{mg}$ and multiple daily doses of up to $20 \mathrm{mg} /$ day, and exhibited a PK profile suitable for a oncedaily dosing regimen [1]. An N-dealkylation primary metabolite of SAM, RDC-9986, was identified in liver microsomes from all species (mouse, rat, dog, and human) and in in vivo PK studies in animals [12].

SAM demonstrates increased exposure following oral and sublingual administration compared with other orally available opioid antagonists, including naloxone and naltrexone (both with oral bioavailability $\leq 5 \%$ ), and exhibits potent and sustained blockade of opioid agonism, which may result in antagonist activity at lower doses relative to naltrexone [1, $5,13,14]$. However, there is currently no published information on the bioavailability of SAM. Given its sublingual/ oral administrative route, determination of absolute bioavailability, i.e. the rate and extent to which a drug reaches the systemic circulation, is of particular importance. Low absolute bioavailability increases the interindividual variability of exposure to a drug, and can indicate poor performance of the formulation and/or poor absorption, as well as extensive first-pass metabolism $[15,16]$.

Co-administration with food can result in drug-food interactions, which may impact bioavailability by altering the rate and extent of drug absorption in the gastrointestinal tract $[17,18]$. Given that all PK evaluations of SAM to date have been conducted in the fasted state, it is important to determine whether a food effect is of potential clinical relevance to SAM. Furthermore, age and gender are also factors recognized to influence bioavailability, and thus an investigation into the impact of age and gender on drug exposure will help inform decisions on the appropriateness of SAM in a wide range of patients $[1,19,20]$.

We describe two phase I PK studies of SAM in healthy volunteers. The first study (ALK33-B107; ClinicalTrials.gov identifier: NCT02504463) compared the PK of SAM following single sublingual, oral, and intravenous doses in fasted male adults. The $2 \mathrm{mg}$ dose of SAM selected for sublingual and oral use in this trial is the dose of SAM in the sublingual co-formulation with buprenorphine for major depressive disorder. The second study (ALK33-009) investigated safety, tolerability, and the effects of food, gender, and age on the PK of a single oral dose of SAM. The $10 \mathrm{mg}$ dose of SAM selected in this second trial is the dose of SAM in the oral co-formulation with olanzapine for schizophrenia.

\section{Methods}

\subsection{Materials}

SAM preparations were manufactured by Alkermes, Inc. for both studies (study 1: Irix Manufacturing, Inc., Greenville, SC, USA; study 2: Cambridge Major Laboratories, Inc., Germantown, WI, USA). In study 1 , the intravenous dose was $1 \mathrm{mg}$ SAM in $5 \mathrm{~mL}$ saline without $\left[{ }^{14} \mathrm{C}\right]$ label, administered as a slow bolus injection over approximately $1 \mathrm{~min}$ (at a rate of approximately $0.07 \mathrm{~mL} / \mathrm{min} / \mathrm{kg}$ for an average participant weighing $70 \mathrm{~kg}$ ). The sublingual dose was $2 \mathrm{mg}$ SAM combined with approximately $50 \mu \mathrm{Ci}$ $\left[{ }^{14} \mathrm{C}\right]$-labeled SAM pipetted onto a sublingual placebo, and the oral dose was $2 \mathrm{mg}$ SAM combined with approximately $50 \mu \mathrm{Ci}\left[{ }^{14} \mathrm{C}\right]$-labeled SAM in a $10 \mathrm{~mL}$ solution. In study 2 , SAM was administered as a $10 \mathrm{mg}$ oral capsule and placebo treatment was a matched lactose-containing capsule.

\subsection{Study Design and Conduct}

Study 1 was a single-center, open-label, fixed-sequence design trial conducted between 25 June and 12 September 2015. Following an initial screening visit (visit 1), healthy male volunteers were admitted to a research unit for a series of three single doses of SAM that were administered during consecutive visits as follows: visit 2 , intravenous ( $1 \mathrm{mg}$ for slow bolus injection over approximately $1 \mathrm{~min}$ ); visit 3, sublingual $(2 \mathrm{mg})$; and visit 4 , oral $(2 \mathrm{mg})$. All doses were administered following an overnight fast of $\geq 10 \mathrm{~h}$, with fasting continuing for $\geq 4 \mathrm{~h}$ postdose. The sublingual and oral doses of SAM were labeled with $\left[{ }^{14} \mathrm{C}\right]-$ SAM (see Sect. 2.1). Each dose period (visits 2, 3, and 4) included at least 8, 14, and 14 days for intravenous, sublingual, and oral administration, respectively. A final follow-up visit (visit 5) occurred approximately 2 weeks after the third dose visit (visit 4).

Plasma samples were collected to determine the PK profiles of SAM and its metabolite (RDC-9986) by liquid chromatography-tandem mass spectrometry (LC-MS/MS) at predose $(0 \mathrm{~h})$, immediately following administration (intravenous dose only), and at 0.25, 0.5, 1, 2, 4, 8, 12, 24, 36 , and $48 \mathrm{~h}$ postdose, with the collection period extending to 72,96 , and $120 \mathrm{~h}$ postdose for the sublingual and oral doses, primarily for the measurement of total radioactivity in blood samples. Urine samples for LC-MS/MS analysis were collected up to $312 \mathrm{~h}$ postdose during the sublingual and oral dose periods. Urine was not collected during the intravenous dose period.

Data collected for measurement of radioactivity by liquid scintillation [not qualified for Good Laboratory 
Practice (GLP) $]$ and determination of the PK of $\left[{ }^{14} \mathrm{C}\right]-\mathrm{SAM}$ (whole blood, plasma, urine, and feces during the sublingual and oral dose periods), as well as collection of additional blood samples for plasma metabolite profiling and identification, are outside the scope of this article and will be described in a separate report.

Study 2 was a single-center, randomized, doubleblind, placebo-controlled, crossover trial in young (aged 18-40 years; cohort 1 ) and elderly (aged $\geq 65$ years; cohort 2 ) healthy adults, with each cohort stratified equally by gender. The study was conducted between 19 July and 23 November 2010.

Following screening procedures, participants were admitted to a research unit the day before dosing. Participants in cohort 1 were randomized 1:1 to 'fed then fasted' or 'fasted then fed' food sequences to be carried out in two dosing periods, separated by a washout period of at least 7 days. Cohort 2 consisted of one dosing period in the fasted state. For both sequences of cohort 1 and for cohort 2, randomization to oral SAM $(10 \mathrm{mg})$ or placebo treatment in a $4: 1$ fashion occurred on the day of dosing. Study treatment was administered following an overnight fast of $\geq 10 \mathrm{~h}$ (fasted state) or $30 \mathrm{~min}$ following a high-calorie, high-fat breakfast (fed state; cohort 1 only). All participants fasted for $4 \mathrm{~h}$ postdose. Blood plasma samples were collected predose $(0 \mathrm{~h})$ and $0.25,0.5,1,2,4,8,12,24$, and $36 \mathrm{~h}$ postdose. All participants returned for a follow-up visit approximately 7 days after their last dosing visit.

\subsection{Study Populations}

In study 1 , male participants were aged $18-55$ years, with a body mass index (BMI) $\geq 19$ and $\leq 32 \mathrm{~kg} / \mathrm{m}^{2}$, and a minimum weight of $50 \mathrm{~kg}$ at screening. Participants were considered to be in good health on the basis of their medical history, physical examination, clinical laboratory tests, vital signs, and electrocardiogram (ECG). Participants who had participated in a clinical study with a $\left[{ }^{14} \mathrm{C}\right]$-labeled drug or with cumulative radiation exposure $>5 \mathrm{mSv}$ within the past 12 months, or $>10 \mathrm{mSv}$ within the past 5 years, were excluded. The target sample size was 10 (with the goal of eight participants completing the study) and was intended to provide reasonable point estimates for mean PK parameters.

In study 2 , male and female adults were aged 18-40 and $\geq 65$ years, with a BMI $\geq 19$ and $\leq 30 \mathrm{~kg} / \mathrm{m}^{2}$, and were in good health at screening. Women of reproductive potential were required to use an approved method of contraception for the study duration. A target sample size of 30 young and 15 elderly participants was considered sufficient to provide an adequate number of participants completing the study (22 young and 11 elderly) with PK data for evaluation within prespecified equivalent exposure limits. For each portion of the study, the targeted number of evaluable subjects would provide $80 \%$ probability that the $90 \%$ confidence interval (CI) for each parameter of interest would fall within the prespecified equivalency limits, provided that the true geometric mean ratio was 1.00 .

In both studies, current or historical drug dependence [as assessed in Diagnostic and Statistical Manual of Mental Disorders, Fourth Edition, Text Revision (DSM-IV-TR) criteria] or a positive urine toxicology screen for cocaine, amphetamines, opioids, or benzodiazepines precluded study participation. ${ }^{1}$

\subsection{Assessments of Safety and Tolerability}

The safety population included all participants who received at least one dose of study drug. Safety monitoring during both studies included the assessment of adverse events, standard clinical laboratory tests, vital signs, ECG results, and physical examination findings.

\subsection{Bioanalysis}

Plasma samples were assayed for SAM and its metabolite, RDC-9986, by LC-MS/MS according to validated GLP methodology as described previously for SAM [1]. The assay had a linear range of $0.250-100 \mathrm{ng} / \mathrm{mL}$, with a lower limit of quantitation of $0.250 \mathrm{ng} / \mathrm{mL}$.

\subsection{Pharmacokinetic (PK) Analysis}

The PK population for each study included participants in the safety population who had at least one plasma sample with a quantifiable concentration of SAM or RDC-9986. Standard PK parameters for SAM and RDC-9986 were calculated from individual concentration-time data by noncompartmental analysis using Phoenix ${ }^{\circledR}$ WinNonlin ${ }^{\circledR}$ software (version 6.1 or 6.2; Certara USA, Inc., Princeton, NJ, USA). The maximum plasma concentration $\left(C_{\max }\right)$ and $t_{\max }$ were obtained directly from concentration data. The AUC from time zero to the time of the last quantifiable concentration $\left(\mathrm{AUC}_{\text {last }}\right)$ was calculated by the mixed linear/logarithmic trapezoidal rule.

The AUC from time zero to infinity $\left(\mathrm{AUC}_{\infty}\right)$ was calculated as $\mathrm{AUC}_{\text {last }}+\left(C_{\text {last }} / \lambda \mathrm{z}\right)$, where $C_{\text {last }}$ was the last measurable plasma concentration, and $\lambda \mathrm{z}$ was the terminal elimination rate constant estimated by log-linear regression analysis of the measured concentrations on the terminal phase of the concentration-time curve. The extrapolated fraction of an individual AUC value had to be below $30 \%$ to be evaluable, which is standard practice in our laboratory for single- and

\footnotetext{
$\overline{{ }^{1} \text { In study } 1}$, urine toxicology screen also included marijuana and
} barbiturates. 
Table 1 Demographics and baseline characteristics (study 1 and study 2)

\begin{tabular}{|c|c|c|c|c|}
\hline \multirow[t]{2}{*}{ Characteristic } & \multirow{2}{*}{$\begin{array}{l}\text { Study } 1 \\
\text { All participants }[N=10]\end{array}$} & \multicolumn{3}{|l|}{ Study 2} \\
\hline & & $\begin{array}{l}\text { Cohort 1 SAM } \\
{[n=24]}\end{array}$ & Cohort 2 SAM $[n=12]$ & Pooled placebo $^{\mathrm{a}}[n=9]$ \\
\hline \multicolumn{5}{|l|}{ Age, years } \\
\hline Mean (SD) & $36.5(9.8)$ & $26.6(6.4)$ & $71.2(4.5)$ & $41.4(22.0)$ \\
\hline Minimum, maximum & 24,54 & 18,39 & 66,80 & 19,74 \\
\hline \multicolumn{5}{|l|}{$\operatorname{Race}[n(\%)]$} \\
\hline White & $6(60.0)$ & $18(75.0)$ & $12(100.0)$ & $9(100.0)$ \\
\hline Black or African American & $3(30.0)$ & $5(20.8)$ & 0 & 0 \\
\hline American Indian or Alaska native & $1(10.0)$ & 0 & 0 & 0 \\
\hline Asian & 0 & $1(4.2)$ & 0 & 0 \\
\hline \multicolumn{5}{|l|}{ Gender $[n(\%)]$} \\
\hline Male & $10(100.0)$ & $12(50.0)$ & $6(50.0)$ & $5(55.6)$ \\
\hline Female & 0 & $12(50.0)$ & $6(50.0)$ & $4(44.4)$ \\
\hline \multicolumn{5}{|l|}{ Weight (kg) } \\
\hline Mean (SD) & $83.53(10.5)$ & $71.1(9.6)$ & $75.8(11.6)$ & $74.9(10.4)$ \\
\hline Minimum, maximum & $63.6,100.6$ & $49.5,93.0$ & $61.4,99.1$ & $53.2,89.1$ \\
\hline \multicolumn{5}{|l|}{ BMI $\left(\mathrm{kg} / \mathrm{m}^{2}\right)$} \\
\hline Mean (SD) & $27.1(2.1)$ & $25.2(2.5)$ & $26.4(1.7)$ & $25.6(3.5)$ \\
\hline Minimum, maximum & $23.8,30.3$ & $19.8,29.4$ & $24.0,28.7$ & $20.1,30.1$ \\
\hline
\end{tabular}

$B M I$ body mass index, $S A M$ samidorphan, $S D$ standard deviation

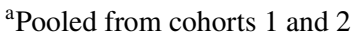

repeated-dose PK studies. The apparent terminal elimination half-life $\left(t_{1 / 2}\right)$ was calculated as $\ln 2 / \lambda \mathrm{z}$, and absolute bioavailability $(F)$ was calculated as $\left(\mathrm{AUC}_{\infty \mathrm{SL}} / \mathrm{Dose}_{\mathrm{SL}}\right)$ / $\left(\mathrm{AUC}_{\infty \mathrm{IV}} /\right.$ Dose $\left._{\mathrm{IV}}\right)$ for the sublingual dose and $\left(\mathrm{AUC}_{\infty \mathrm{PO}} /\right.$ Dose $\left._{\mathrm{PO}}\right) /\left(\mathrm{AUC}_{\infty \mathrm{IV}} /\right.$ Dose $\left._{\mathrm{IV}}\right)$ for the oral dose of SAM. Apparent plasma clearance $(\mathrm{CL} / \mathrm{F})$ was calculated as dose/AUC ${ }_{\infty}$. Renal clearance $\left(\mathrm{CL}_{\mathrm{r}}\right)$ was determined from urine samples (study 1 only) following oral and sublingual administration and was calculated as $X_{\text {last,urine }} / \mathrm{AUC}_{\text {last }}$, where $X_{\text {last,urine }}$ was the total amount of drug excreted in urine from time zero to the time of $C_{\text {last }}$. The metabolite to parent AUC ratio $\left(R_{\mathrm{AUC}}\right)$ was calculated as RDC-9986 $\mathrm{AUC}_{\infty} / \mathrm{SAM} \mathrm{AUC}_{\infty}$ and was adjusted for molecular weight [370.44 and 316.35 (free base) for SAM and RDC-9986, respectively].

\subsection{Statistical Analysis}

All data were evaluated by descriptive statistics. In study 2 , food and age effects were examined using a linear mixed model on log-transformed PK values. Covariates were not applicable. Two-sided $90 \%$ CIs for the geometric least squares mean (GLSM) ratios of $C_{\max }$ and AUC of SAM for the fed/fasted states within the limits of 0.80-1.25 were taken to indicate the absence of a significant food effect, and CIs for elderly/young participants within the limits of $0.70-1.43$ were taken to indicate the absence of a significant age effect. We determined that a less strict standard would be more appropriate for the age comparison because of the greater variability of the data, and because the age-effect study could only be conducted using a parallel comparison design, whereas the food-effect study used a crossover design. No criteria were used for evaluation of the gender effect; the GLSM ratios and CIs of $C_{\max }$ and AUC of SAM for male to female were reported.

\section{Results}

\subsection{Study Population Characteristics}

In study 1 , a total of 10 participants were enrolled and included in the PK and safety populations. Nine participants completed the study and one participant withdrew consent.

In study 2, a total of 45 participants were enrolled, with 15 in each treatment sequence of cohort 1 and 15 in cohort 2 . Within each group of 15,12 were randomized to receive SAM and three were randomized to placebo; all were included in the safety population, with the three participants randomized to placebo in both treatment sequences of cohort 1 and in cohort 2 pooled (i.e. pooled placebo, $n=9$ ). Only those participants randomized to SAM were included in the PK population. Overall, 39 participants completed the study and six discontinued: four participants withdrew consent, one was lost to follow-up, and one had a protocol violation. 


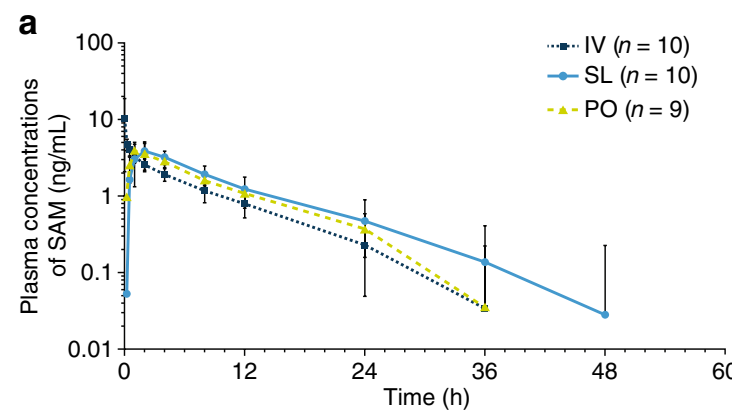

Fig. 1 Mean plasma concentrations of a SAM and b RDC-9986 over time following single IV administration of SAM $1 \mathrm{mg}$, and SL and PO administrations of SAM $2 \mathrm{mg}$ (semi-logarithmic scale). Error bars represent standard deviations of the mean (semi-logarithmic scale). Note: For PL and SL administration, values at 72, 96, and $120 \mathrm{~h}$ were

Demographics and baseline characteristics for both studies are summarized in Table 1.

\subsection{PK of Samidorphan (SAM) Following Sublingual, Oral, and Intravenous Administration (Study 1)}

Mean plasma concentrations of SAM and RDC-9986 after a single intravenous, sublingual, or oral dose are shown in Fig. 1. Mean plasma and urine PK parameters, which were determined using non-compartmental methods, are listed in Table 2.

The PK profiles for both SAM and RDC-9986 were comparable after oral and sublingual administration. Mean plasma concentrations of SAM and RDC-9986 reached maximum levels within $2 \mathrm{~h}$ of a single $2 \mathrm{mg}$ sublingual administration and within $1 \mathrm{~h}$ of a single $2 \mathrm{mg}$ oral administration (Fig. 1). Subsequently, plasma concentrations decreased mono-exponentially for SAM (Fig. 1a) and bi-exponentially for RDC-9986 (Fig. 1b), with a rapid distribution phase and a slow elimination phase.

Following a single intravenous bolus injection of SAM $(1 \mathrm{mg})$, mean plasma concentrations of SAM declined in a manner similar to that seen with the oral and sublingual routes of administration. Maximum plasma levels of RDC9986 were reached within a median of $2.5 \mathrm{~h}$ after intravenous administration of SAM (Table 2), and declined slowly thereafter, although a terminal elimination phase could not be clearly defined.

Mean values for key PK parameters, including $t_{\max }, C_{\max }$, apparent plasma clearances, and $t_{1 / 2}$, were similar following oral and sublingual administration. The elimination half-life of SAM by the intravenous route was similar to the sublingual and oral elimination half-lives, with a mean value ranging from 7 to $9 \mathrm{~h}$. The elimination half-lives for RDC-9986 were longer than that of SAM; the mean value was $26 \mathrm{~h}$ by the sublingual route and $23 \mathrm{~h}$ by the oral route. Mean $R_{\mathrm{AUC}}$

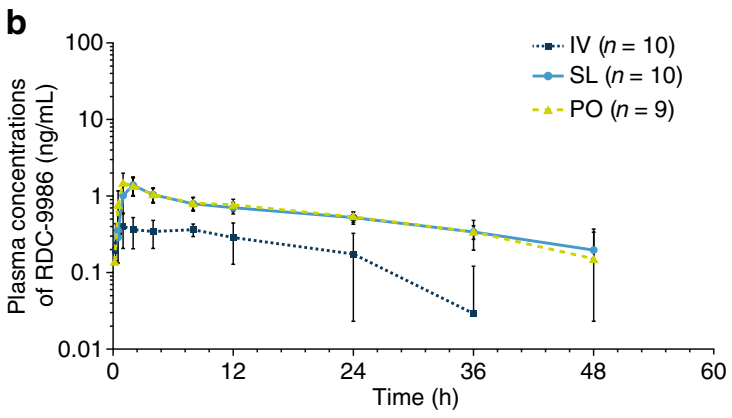

all below the LLOQ. In these graphs, mean values could be below the LLOQ because measurements below the LLOQ occurring before the first measurable value and after the last measurable value were included and assigned a value of 0 . $S A M$ samidorphan, $I V$ intravenous, $L L O Q$ lower limit of quantification, $P O$ oral, $S L$ sublingual

values for RDC-9986/SAM were $0.314,0.818$, and 0.981 following intravenous, sublingual, and oral administration of SAM, respectively.

SAM was well-absorbed, with $20.4 \%$ (sublingual) and $18.8 \%$ (oral) excreted unchanged in urine following administration (Table 2). Average $\mathrm{CL}_{\mathrm{r}}$ for SAM and RDC-9986 was approximately $11 \mathrm{~L} / \mathrm{h}(183 \mathrm{~mL} / \mathrm{min})$ and $18 \mathrm{~L} / \mathrm{h}(300 \mathrm{~mL} /$ min), which approximates or exceeds normal glomerular filtration rate. For both SAM and RDC-9986, mean $\mathrm{CL}_{\mathrm{r}}$ was similar following sublingual and oral exposure (Table 2).

\subsection{Absolute Bioavailability of SAM Following Sublingual and Oral Administration (Study 1)}

Mean AUC values were similar following sublingual and oral administration of $2 \mathrm{mg} \mathrm{SAM}$ (Table 2), and hence the average absolute bioavailability for the sublingual route of administration (mean 71.2\%; range $62.9-80.3 \% ; n=10$ ) was similar to that observed for the oral route of administration (mean 68.6\%; range 60.3-82.6\%; $n=9$ ).

\subsection{Effect of Food, Age, and Gender on SAM PK (Study 2)}

Mean PK profiles for SAM and RDC-9986 following a $10 \mathrm{mg}$ oral dose of SAM, according to food, age, and gender, are shown in Fig. 2, and the PK parameter estimates are shown in Tables 3 and 4.

Concentration-time profiles following oral administration of SAM $(10 \mathrm{mg})$ in cohort 1 were similar under fed and fasted conditions (Fig. 2a). One female participant vomited within $3 \mathrm{~h}$ of administration of SAM during the fed regimen and was excluded from the overall analysis. SAM was rapidly absorbed, with median $t_{\max }$ reached at $2 \mathrm{~h}$ in the fasted state and $4 \mathrm{~h}$ in the fed state (Table 3). Despite a slight delay in $t_{\max }$ under the fed state, the systemic exposure and 


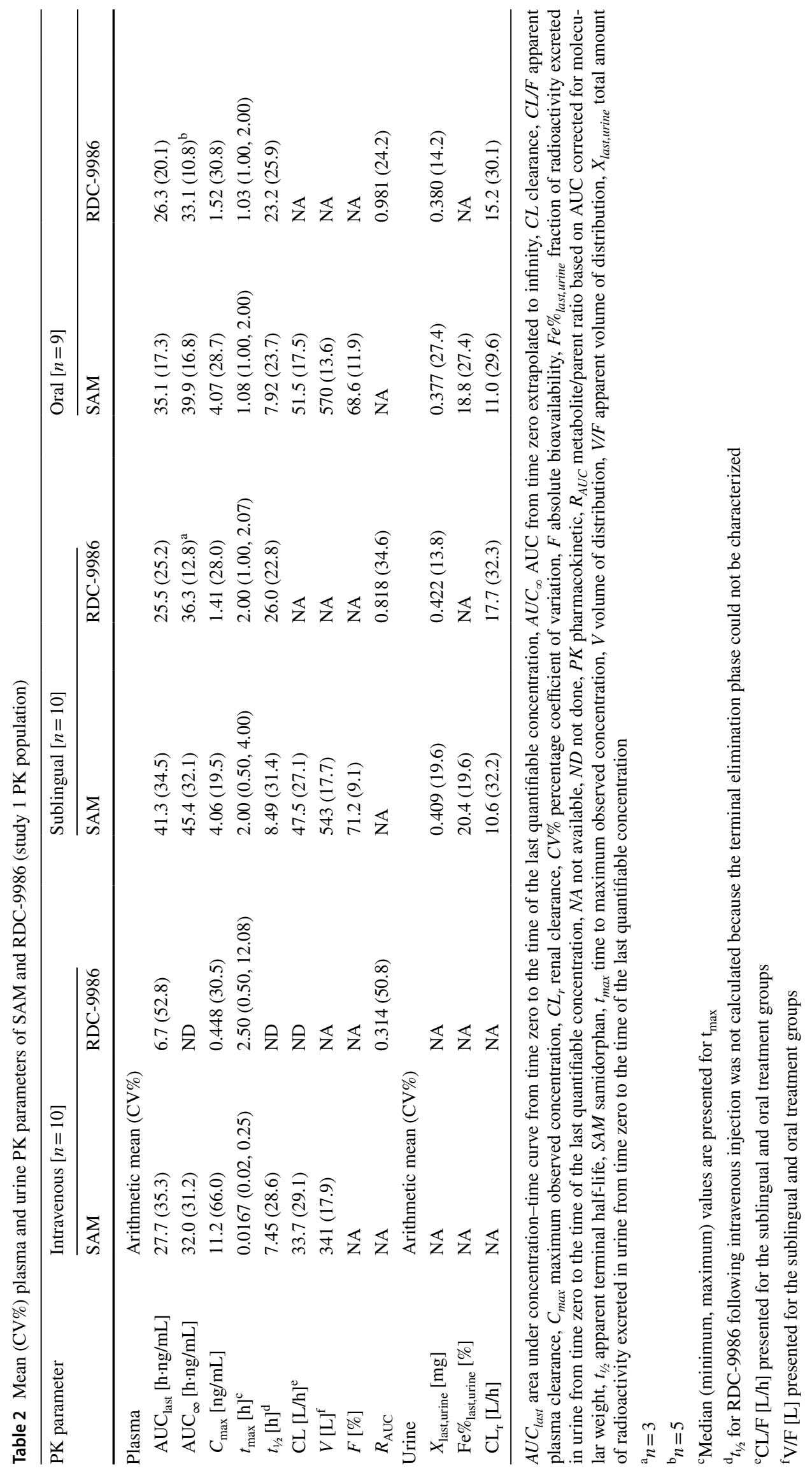



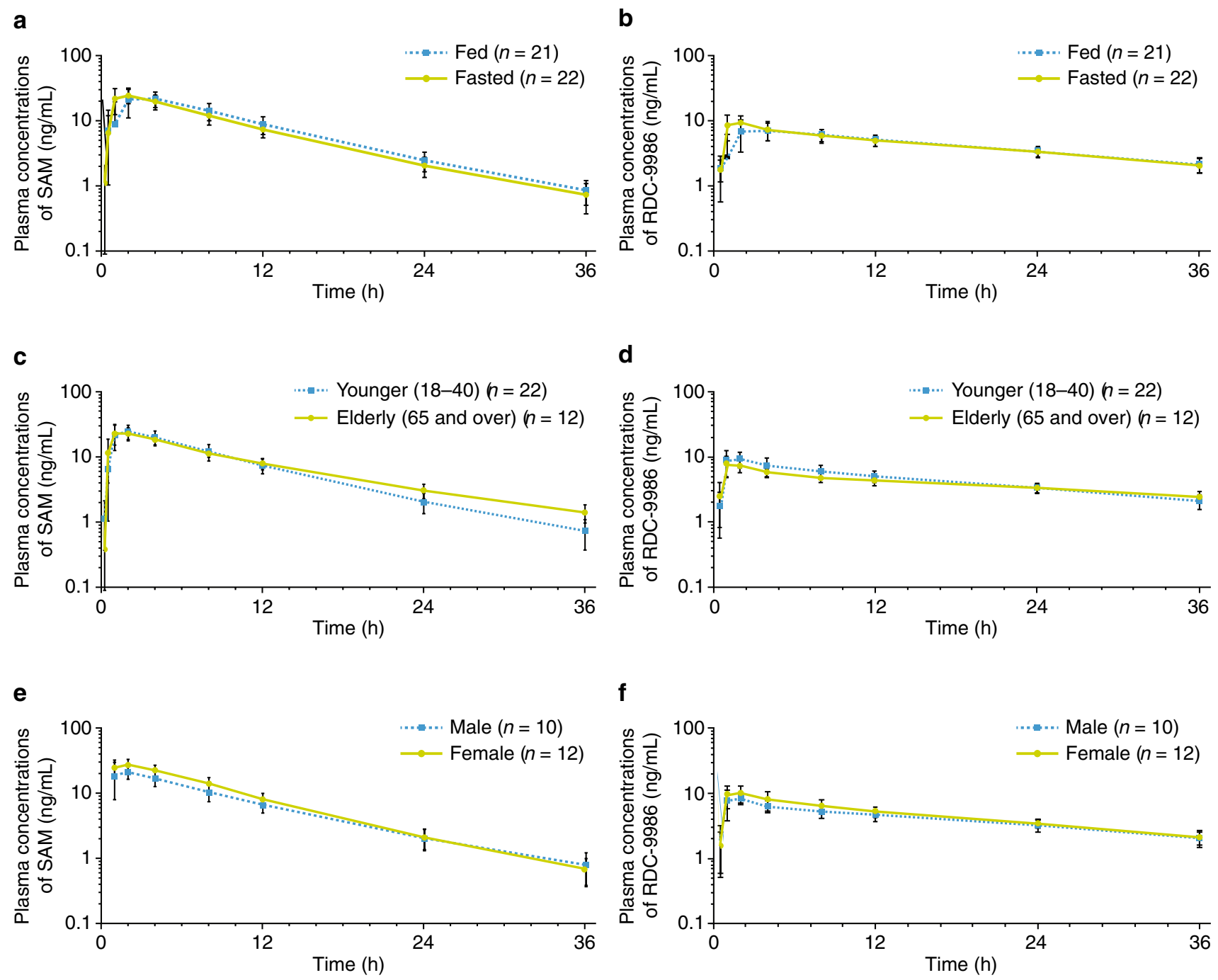

Fig. 2 Mean plasma concentration time course of SAM and RDC9986 following single oral administration of SAM $10 \mathrm{mg}$. Effect of food on a SAM and b RDC-9986; effect of age under fasting condi-

elimination $t_{1 / 2}$ remained similar. In each food state, SAM concentrations decreased linearly when plotted using logtransformed concentration data, with measurable concentrations present through $36 \mathrm{~h}$ postdose. The $90 \%$ CIs for the GLSM ratios of $C_{\max }$ and $\mathrm{AUC}_{\infty}$ for the fed/fasted states fell within the prespecified $0.80-1.25$ window of equivalence (Table 5), thereby excluding a significant effect of food on the PK of SAM.

When the young participants in cohort 1 and elderly participants in cohort 2 were compared in the fasted state, the $90 \%$ CIs for the GLSM ratios of $C_{\text {max }}, \mathrm{AUC}_{\text {last }}$, and $\mathrm{AUC}_{\infty}$ fell within the prespecified interval of 0.70-1.43 (Table 5), indicating the absence of a significant effect of age on the systemic exposure of SAM. Based on a direct comparison of the median values for $t_{\max }$, no notable difference by age group was evident (Table 3). As shown in Fig. 2c, the

tions on c SAM and d RDC-9986; and effect of gender under fasting conditions on e SAM and f RDC-9986. Error bars represent standard deviations of the mean (semi-logarithmic scale). SAM samidorphan

terminal elimination phase was longer in the elderly participants, resulting in a slightly increased half-life and reduced $\mathrm{CL} / F$ compared with the young participants.

Cohort 1 had 10 males and 12 females and cohort 2 had 6 males and 6 females who were dosed under fasted conditions. For young and elderly adults from both cohorts, systemic exposure appeared to be slightly higher in females than in males (Table 3). Within the pooled data across cohorts 1 and 2, the GLSM ratios for systemic exposure of SAM $\left(C_{\text {max }}, \mathrm{AUC}_{\text {last }}\right.$, and $\left.\mathrm{AUC}_{\infty}\right)$ were approximately 1.2-fold higher in female participants than male participants (Table 5).

Mean PK profiles for RDC-9986 following a $10 \mathrm{mg}$ oral dose of SAM were similar with respect to food, age, and gender (Fig. 2b, d, and f). A descriptive comparison of mean systemic exposures to RDC-9986 showed no apparent 
Table 3 Descriptive statistics for plasma PK parameters of SAM according to food, age, and gender

\begin{tabular}{|c|c|c|c|c|c|c|c|}
\hline \multirow[t]{2}{*}{ PK parameter ${ }^{\mathrm{a}}$} & \multicolumn{2}{|l|}{ Cohort 1: Young } & \multirow{2}{*}{$\begin{array}{l}\text { Cohort 2: } \\
\text { Elderly } \\
\text { Fasted }[n=12]\end{array}$} & \multirow{2}{*}{$\begin{array}{l}\text { Cohort 1: } \\
\text { Female } \\
\text { Fasted }[n=12]\end{array}$} & \multirow{2}{*}{$\begin{array}{l}\text { Cohort 1: Male } \\
\text { Fasted }[n=10]\end{array}$} & \multirow{2}{*}{$\begin{array}{l}\text { Cohort 2: } \\
\text { Female } \\
\text { Fasted }[n=6]\end{array}$} & \multirow{2}{*}{$\begin{array}{l}\text { Cohort 2: Male } \\
\text { Fasted }[n=6]\end{array}$} \\
\hline & Fed [ & Fast & & & & & \\
\hline$C_{\max }[\mathrm{ng} / \mathrm{mL}]$ & $25.26(8.16)$ & $26.24(6.83)$ & $25.28(6.16)$ & $28.83(5.19)$ & $23.13(7.50)$ & $26.88(6.33)$ & $23.68(6.11)$ \\
\hline $\begin{array}{l}t_{\max }[\mathrm{h} ; \text { median } \\
\quad(\text { range) }]\end{array}$ & $4.00(1.0-4.02)$ & $2.00(1.00-4.00)$ & $\begin{array}{l}1.00(1.00- \\
2.00)\end{array}$ & $2.00(1.00-4.00)$ & $2.00(1.00-4.00)$ & $2.00(1.00-2.00)$ & $1.00(1.00-2.00)$ \\
\hline $\begin{array}{l}\mathrm{AUC}_{\text {last }}[\mathrm{h} \cdot \mathrm{ng} / \\
\mathrm{mL}]\end{array}$ & 266. & 24 & $262.80(41.06)$ & 26 & 220 & 28 & 9.46) \\
\hline $\begin{array}{l}\mathrm{AUC}_{\infty}[\mathrm{h} \cdot \mathrm{ng} / \\
\mathrm{mL}]\end{array}$ & 16) & 25 & 28 & 2 & 22 & 25 & 26 \\
\hline$t_{1 / 2}[\mathrm{~h}]$ & 0.95 & 6 & 9 & 6. & 7. & 8.9 & 10 \\
\hline $\mathrm{Vz} / F[\mathrm{~L}]$ & $386.56(106.22)$ & $407.95(115$ & $495.58(110.28)$ & $336.59(75.42)$ & 486.45 (101. & $433.56(54.77)$ & $557.60(120.51)$ \\
\hline $\mathrm{CL} / F[\mathrm{~L} / \mathrm{h}]$ & $38.78(10.68)$ & 40.91 (10.97) & $36.31(6.23)$ & $36.22(7.95)$ & 46.07 (11.87) & $34.10(5.36)$ & $38.52(6.72)$ \\
\hline
\end{tabular}

$A U C_{\text {last }}$ area under concentration-time curve from time zero to the time of the last quantifiable concentration, $A U C_{\infty}$ AUC from time zero extrapolated to infinity, $C L / F$ apparent plasma clearance, $C_{\max }$ maximum observed concentration, $P K$ pharmacokinetic, $S A M$ samidorphan, $t_{1 / 2}$ apparent terminal half-life, $t_{\max }$ time to maximum observed concentration, $V z / F$ apparent volume of distribution

${ }^{a}$ All values are presented as mean (standard deviation) except where noted

Table 4 Descriptive statistics for plasma PK parameters of RCD-9986 according to food, age, and gender

\begin{tabular}{|c|c|c|c|c|c|c|c|}
\hline \multirow[t]{2}{*}{ PK parameter ${ }^{\mathrm{a}}$} & \multicolumn{2}{|l|}{ Cohort 1: Young } & \multirow{2}{*}{$\begin{array}{l}\text { Cohort 2: } \\
\text { Elderly } \\
\text { Fasted }[n=12]\end{array}$} & \multirow{2}{*}{$\begin{array}{l}\text { Cohort 1: } \\
\text { Female } \\
\text { Fasted }[n=12]\end{array}$} & \multirow{2}{*}{$\begin{array}{l}\text { Cohort 1: Male } \\
\text { Fasted }[n=10]\end{array}$} & \multirow{2}{*}{$\begin{array}{l}\text { Cohort 2: } \\
\text { Female } \\
\text { Fasted }[n=6]\end{array}$} & \multirow{2}{*}{$\begin{array}{l}\text { Cohort 2: Male } \\
\text { Fasted }[n=6]\end{array}$} \\
\hline & Fed $[n=20]$ & Fasted $[n=22]$ & & & & & \\
\hline$C_{\max }[\mathrm{ng} / \mathrm{mL}]$ & $8.14(2.71)$ & $10.19(2.76)$ & $8.32(2.17)$ & $11.02(2.99)$ & $9.19(2.21)$ & $8.52(1.72)$ & $8.13(2.70)$ \\
\hline $\begin{array}{l}t_{\max }[\mathrm{h} ; \text { median } \\
\quad(\text { range) }]\end{array}$ & $\begin{array}{l}4.00(1.00- \\
12.03)\end{array}$ & $\begin{array}{l}2.00(1.00- \\
4.00)\end{array}$ & $\begin{array}{l}1.00(1.00- \\
2.00)\end{array}$ & $\begin{array}{l}1.50(1.00- \\
2.00)\end{array}$ & $\begin{array}{l}2.00(1.00- \\
4.00)\end{array}$ & $\begin{array}{l}1.50(1.00- \\
2.00)\end{array}$ & $-2.00)$ \\
\hline $\begin{array}{l}\mathrm{AUC}_{\text {last }}[\mathrm{h} \cdot \mathrm{ng} / \\
\mathrm{mL}]\end{array}$ & $151.69(29.58)$ & $154.42(37.11)$ & $143.40(21.76)$ & $160.32(45.45)$ & $147.33(24.21)$ & $150.96(9.48)$ & $135.83(28.55)$ \\
\hline $\begin{array}{l}\mathrm{AUC}_{\infty}{ }^{\mathrm{b}}[\mathrm{h} \cdot \mathrm{ng} / \\
\mathrm{mL}]\end{array}$ & 207.3 & 211. & A) & 49.98) & 5.13) & (NA) & NA \\
\hline$t_{1 / 2}[\mathrm{~h}]$ & $16.90(1.90)$ & $17.42(2.31)$ & $17.75(\mathrm{NA})$ & $16.50(2.38)$ & $18.48(1.83)$ & $17.75(\mathrm{NA})$ & $\mathrm{NA}(n=0)$ \\
\hline
\end{tabular}

$A U C_{\text {last }}$ area under concentration-time curve from time zero to the time of the last quantifiable concentration, $A U C_{\infty}$ AUC from time zero extrapolated to infinity, $\% A U C_{e x}$ percentage of $\mathrm{AUC}_{\infty}$ due to extrapolation from the time of the last measurable concentration, $C_{\max }$ maximum observed concentration, $P K$ pharmacokinetic, $R s q$ goodness-of-fit statistic for the terminal elimination phase, $t_{1 / 2}$ apparent terminal half-life, $t_{m a x}$ time to maximum observed concentration

${ }^{a}$ All values are presented as mean (standard deviation) except where noted

${ }^{\mathrm{b}} \mathrm{A}$ minimum of three data points were used for each terminal phase determination. If the Rsq value was $<0.80$ or the $\% \mathrm{AUC}_{\mathrm{ex}}$ was $>30, \mathrm{AUC}_{\infty}$ was set to missing

differences with respect to the effect of food, age, and gender (Table 4).

\subsection{Safety}

SAM was generally well tolerated across both studies, and no deaths, serious adverse events, or adverse events leading to treatment discontinuation were reported (Table 6). Adverse events were generally gastrointestinal or neurological in nature and predominantly mild or moderate in intensity (Table 6). The adverse events reported in two or more participants of study 1 included infrequent bowel movements, nausea, abdominal pain, and headache. In study 2, adverse events in three or more participants receiving SAM in either cohort 1 or cohort 2 were nausea, dizziness, somnolence, headache, vomiting, and hot flush (Table 6). No adverse events were reported in two or more participants of the pooled placebo group $(N=9)$. The incidence and pattern of adverse events in participants receiving SAM did not appear to be influenced by food, age, or gender. Mean changes from baseline in laboratory parameters (hematology, chemistry, and urinalysis), vital signs, and 12-lead ECG parameters were not clinically meaningful between treatment groups in either study. 
Table 5 Evaluation of food, age, and gender on the PK parameters of SAM following single oral administration of SAM 10 mg (study 2 PK population)

\begin{tabular}{|c|c|c|c|}
\hline PK parameter & Geometric least squares mean & & $\begin{array}{l}\text { Geometric least } \\
\text { squares mean ratio } \\
(90 \% \mathrm{CI})\end{array}$ \\
\hline Food $^{\mathrm{a}}$ & Fed: Cohort $1[n=20]$ & Fasted: Cohort $1[n=22]$ & Fed/fasted \\
\hline$C_{\max }[\mathrm{ng} / \mathrm{mL}]$ & 24.25 & 25.32 & $0.96(0.83-1.11)$ \\
\hline $\mathrm{AUC}_{\text {last }}[\mathrm{h} \cdot \mathrm{ng} / \mathrm{mL}]$ & 251.13 & 234.61 & $1.07(1.02-1.12)$ \\
\hline $\mathrm{AUC}_{\infty}[\mathrm{h} \cdot \mathrm{ng} / \mathrm{mL}]^{\mathrm{b}}$ & 266.94 & $249.74^{\mathrm{c}}$ & $1.07(1.02-1.12)$ \\
\hline Age $^{\mathrm{d}}$ & Elderly: Cohort 2 [n=12] & Young: Cohort $1[n=22]$ & Elderly/Young \\
\hline$C_{\max }[\mathrm{ng} / \mathrm{mL}]$ & 24.60 & 25.35 & $0.97(0.83-1.14)$ \\
\hline $\mathrm{AUC}_{\text {last }}[\mathrm{h} \cdot \mathrm{ng} / \mathrm{mL}]$ & 259.73 & 236.26 & $1.10(0.94-1.28)$ \\
\hline $\mathrm{AUC}_{\infty}[\mathrm{h} \cdot \mathrm{ng} / \mathrm{mL}]^{\mathrm{b}}$ & 278.99 & $251.98^{\mathrm{c}}$ & $1.11(0.97-1.27)$ \\
\hline Gender $^{\mathrm{e}}$ & Female: Cohorts 1 and $2[n=18]$ & Male: Cohorts 1 and $2[n=16]$ & Female/Male \\
\hline$C_{\max }[\mathrm{ng} / \mathrm{mL}]$ & 27.67 & 22.46 & $1.23(1.07-1.42)$ \\
\hline $\mathrm{AUC}_{\text {last }}[\mathrm{h} \cdot \mathrm{ng} / \mathrm{mL}]$ & 262.80 & 225.02 & $1.17(1.01-1.35)$ \\
\hline $\mathrm{AUC}_{\infty}[\mathrm{h} \cdot \mathrm{ng} / \mathrm{mL}]^{\mathrm{b}}$ & $286.33^{\mathrm{f}}$ & 237.45 & $1.21(1.07-1.36)$ \\
\hline
\end{tabular}

$A N O V A$ analysis of variance, $A U C_{\text {last }}$ area under concentration-time curve from time zero to the time of the last quantifiable concentration, $A U C_{\infty}$ AUC from time zero extrapolated to infinity, $C I$ confidence interval, $C_{\max }$ maximum observed concentration, $\% A U C_{e x}$ percentage of AUC ${ }_{\infty}$ due to extrapolation from the time of the last measurable concentration, $P K$ pharmacokinetic, $R s q$ goodness-of-fit statistic for the terminal elimination phase, SAM samidorphan

${ }^{a}$ Calculated from the ANOVA model with food category as the main effect using only cohort 1 . The effect of food on SAM PK was studied in cohort 1 (fed) and cohort 1 (fasted). Twenty participants were analyzed in cohort 1 (fed), and 22 participants were analyzed in cohort 1 (fasted)

${ }^{\mathrm{b}} \mathrm{A}$ minimum of three data points were used for each terminal phase determination. If the Rsq value was $<0.80$ or the $\% \mathrm{AUC}_{\mathrm{ex}}$ was $>30, \mathrm{AUC}_{\infty}$ was set to missing

${ }^{\mathrm{c}} n=21$

${ }^{\mathrm{d}}$ Calculated from the ANOVA model with age as the main effect using only fasting regimens. The effect of age on SAM PK was studied in cohort 1 (young; age 18-40 years) and cohort 2 (elderly; age $\geq 65$ years) under fasting conditions. Twenty-two participants were analyzed in cohort 1 , and 12 participants were analyzed in cohort 2

${ }^{\mathrm{e}}$ Calculated from the ANOVA model with gender as the main effect using only the fasting regimens. Cohort 1 had 10 males and 12 females who were dosed under fasting conditions; cohort 2 had six males and six females dosed under fasting conditions. For statistical analysis, the participants were pooled across the two cohorts by gender for an exploratory analysis ${ }^{\mathrm{f}} n=17$

\section{Discussion}

These phase I studies provide additional data on the PK profile of single sublingual, oral, and intravenous administrations of the novel $\mu$-opioid receptor antagonist SAM. Following a single intravenous bolus dose of $1 \mathrm{mg}$ SAM, the PK of SAM was characterized by a plasma clearance of $33.7 \mathrm{~L} / \mathrm{h}$, a volume of distribution of $341 \mathrm{~L}$, and an elimination half-life of $7-8 \mathrm{~h}$ (study 1 ). Following a single sublingual or oral administration of $2 \mathrm{mg}$ SAM, SAM was well-absorbed and reached peak concentrations within $2 \mathrm{~h}$ and had similar absolute sublingual and oral bioavailability of $71 \%$ and $69 \%$, respectively. Approximately $20 \%$ of the sublingual or oral dose was excreted as SAM in urine. The elimination half-life was similar for the three routes of administration. For SAM and its metabolite, RDC-9986, there were no large differences in $\mathrm{AUC}, C_{\max }$, and $t_{\max }$ between the sublingual and oral routes of administration (Table 2).

The high and comparable absolute bioavailability of SAM following sublingual and oral administration indicated that SAM has good permeability and is not subject to extensive first-past metabolism, in contrast to other available opioid receptor antagonists, including naloxone and naltrexone $[1,13,14,21,22]$. The relatively low $(<5 \%)$ oral and sublingual bioavailability of naloxone limits its clinical utility when administered via these routes [14, 21, 22]. Naltrexone undergoes rapid and extensive first-pass metabolism after oral administration, with large variation in bioavailability (from 5 to $60 \%$ ) [23]. Due to physiochemical limitations, it is not feasible to administer the dose of naltrexone required for $\mu$-opioid receptor blockade sublingually [24].

Food is known to impact the bioavailability of selected drugs when consumed concurrently, by altering the rate 
Table 6 Summary of treatment-emergent AEs of the safety population (studies 1 and 2)

\begin{tabular}{|c|c|c|c|c|c|c|}
\hline \multirow[t]{2}{*}{$\mathrm{AE}[n(\%)]$} & \multicolumn{2}{|l|}{ Study 1} & \multicolumn{4}{|l|}{ Study 2} \\
\hline & $\begin{array}{l}\text { Intravenous } \\
\text { SAM }[n=10]\end{array}$ & $\begin{array}{l}\text { Sublingual } \\
\text { SAM }[n=10]\end{array}$ & Oral SAM $[n=9]$ & $\begin{array}{l}\text { Cohort } 1 \\
\text { Active }[n=24]\end{array}$ & $\begin{array}{l}\text { Cohort } 2 \\
\text { Active }[n=12]\end{array}$ & $\begin{array}{l}\text { Pooled } \\
\text { Placebo } \\
{[n=9]}\end{array}$ \\
\hline Any AE & $2(20)$ & $5(50)$ & $4(44)$ & $22(92)$ & $10(83)$ & $3(33)$ \\
\hline Any severe $\mathrm{AE}$ & 0 & 0 & 0 & $4(17)$ & $1(8)$ & 0 \\
\hline Any SAE & 0 & 0 & 0 & 0 & 0 & 0 \\
\hline AE leading to discontinuation & 0 & 0 & 0 & 0 & 0 & 0 \\
\hline \multicolumn{7}{|c|}{ AEs occurring in two or more patients } \\
\hline Infrequent bowel movements & 0 & $2(20)$ & $2(22)$ & 0 & $2(17)$ & 0 \\
\hline Constipation & 0 & 0 & 0 & 0 & $2(17)$ & 0 \\
\hline Nausea & $1(10)$ & $2(20)$ & $1(11)$ & $15(63)$ & $6(50)$ & 0 \\
\hline Abdominal pain & 0 & 0 & $2(22)$ & $1(4)$ & $1(8)$ & 0 \\
\hline Abdominal discomfort & 0 & 0 & 0 & $1(4)$ & $1(8)$ & 0 \\
\hline Diarrhea & 0 & 0 & 0 & $1(4)$ & $1(8)$ & 0 \\
\hline Headache & $1(10)$ & $2(20)$ & $1(11)$ & $5(21)$ & $5(42)$ & $1(11)$ \\
\hline Dizziness & 0 & 0 & 0 & $7(29)$ & $6(50)$ & 0 \\
\hline Somnolence & 0 & 0 & 0 & $9(38)$ & $3(25)$ & 0 \\
\hline Vomiting & $1(10)$ & 0 & 0 & $8(33)$ & $1(8)$ & 0 \\
\hline Hot flush & 0 & 0 & 0 & $3(13)$ & $1(8)$ & 0 \\
\hline Dry mouth & 0 & 0 & 0 & 0 & $2(17)$ & 0 \\
\hline Decreased appetite & 0 & 0 & 0 & $2(8)$ & 0 & 0 \\
\hline
\end{tabular}

$A E s$ adverse events, SAE serious AE, SAM samidorphan

and extent of drug absorption $[17,18]$. In the current study, equivalence between the fed and fasted states was established for orally administered SAM in healthy volunteers, indicating that the extent of absorption is not affected by the presence of food in the gastrointestinal tract.

PK studies published to date have focused on oral administration of SAM in healthy, predominantly younger, male participants [1]. The inclusion of elderly participants (age $\geq 65$ years) in the current investigation provides important data confirming the lack of an age effect on the oral dose of SAM. Although the slightly higher systemic exposure of oral SAM in females than males is of potential interest, this study was not powered to detect gender differences. Moreover, the high degree of collinearity of body weight, BMI, and gender complicate the interpretation of these data.

The major metabolite of SAM, RDC-9986, was measurable in the plasma following intravenous, sublingual, and oral administration of SAM, with a mean exposure ratio to SAM of approximately 1 after molecular weight adjustment, and a longer $t_{1 / 2}$ (mean: $17-23 \mathrm{~h}$ vs. 7-9 h for SAM) with no overlap in ranges. However, RDC-9986 is not expected to contribute to the pharmacologic effects of SAM based on the known in vitro and in vivo pharmacology. In vitro, SAM acts as an antagonist at $\mu$-opioid receptors with relatively high binding affinity ( $K_{i}$ value of $\left.0.052 \mathrm{nM}\right)$ and as a partial agonist at $\kappa$-opioid receptors with relatively lower binding affinity ( $K_{i}$ value of $0.23 \mathrm{nM}$ ), whereas RDC-9986 functions as an agonist with relatively low binding to $\mu$-opioid receptors $\left(K_{i}\right.$ value of $\left.0.26 \mathrm{nM}\right)$ and much lower binding to $\kappa$-opioid receptors (data on file, Alkermes). No $\mu$ - or $\kappa$-agonist activity of RDC-9986 has been observed to date in any of the preclinical or clinical evaluations [25-27].

\section{Conclusions}

Overall, these PK studies indicate that SAM has high permeability and bioavailability that are comparable following sublingual and oral administration, and SAM is not subjected to extensive first-pass metabolism. Equivalence between the fed and fasted states shows that the extent of absorption of orally administered SAM is not affected by food. SAM was generally well tolerated, and no new safety signals were detected.

Acknowledgements The authors thank the study participants, as well as the study investigators and research personnel. For study 1, we thank Rebecca Wood-Horrall, MD, Rahul Bhatnagar, MD, Tiffany Reyes, Yue Song, Eric Zimmerman, PhD, and Mei Li of PPD, and Arielle D. Stanford, MD, of Alkermes, Inc. For study 2, we thank Stephen Daniels, DO, John Morgan, MD, Xiaoa Zhen, PhD, and James McDowell, MD, of Premier Research Group Limited, and Bernard Silverman, MD, 
Lauren DiPetrillo, $\mathrm{PhD}$, and Asli Memisoglu, ScD, of Alkermes, Inc. These studies were sponsored by Alkermes, Inc. Medical writing assistance was funded by Alkermes, Inc., and provided by Eleanor J. Finn, $\mathrm{PhD}$, and Henry Caporoso, MA, of Parexel International.

\section{Compliance with Ethical Standards}

Conflict of interest Vipul Kumar, Hong Lu, Marjie Hard, and Lisa von Moltke were all employees of Alkermes Inc. at the time the study was conducted and at the time the manuscript was written and submitted.

Open Access This article is distributed under the terms of the Creative Commons Attribution-NonCommercial 4.0 International License (http://creativecommons.org/licenses/by-nc/4.0/), which permits any noncommercial use, distribution, and reproduction in any medium, provided you give appropriate credit to the original author(s) and the source, provide a link to the Creative Commons license, and indicate if changes were made.

\section{References}

1. Turncliff R, DiPetrillo L, Silverman B, Ehrich E. Single- and multiple-dose pharmacokinetics of samidorphan, a novel opioid antagonist, in healthy volunteers. Clin Ther. 2015;37(2):338-48.

2. Wentland MP, Lou R, Lu Q, et al. Syntheses of novel high affinity ligands for opioid receptors. Bioorg Med Chem Lett. 2009;19(8):2289-94.

3. Wentland MP, Lu Q, Lou R, Bu Y, Knapp BI, Bidlack JM. Synthesis and opioid receptor binding properties of a highly potent 4-hydroxy analogue of naltrexone. Bioorg Med Chem Lett. 2005;15(8):2107-10.

4. Wentland MP, Sun X, Bu Y, Lou R, Cohen DJ, Bidlack JM. Redefining the structure-activity relationships of 2,6-methano-3-benzazocines. Part 3: 8-Thiocarboxamido and 8-thioformamido derivatives of cyclazocine. Bioorg Med Chem Lett. 2005;15(10):2547-51.

5. Ehrich E, Turncliff R, Du Y, et al. Evaluation of opioid modulation in major depressive disorder. Neuropsychopharmacology. 2015;40(6):1448-55.

6. Fava M, Memisoglu A, Thase ME, et al. Opioid modulation with buprenorphine/samidorphan as adjunctive treatment for inadequate response to antidepressants: a randomized double-blind placebo-controlled trial. Am J Psychiatry. 2016;173(5):499-508.

7. Shram MJ, Silverman B, Ehrich E, Sellers EM, Turncliff R. Use of remifentanil in a novel clinical paradigm to characterize onset and duration of opioid blockade by samidorphan, a potent mu-receptor antagonist. J Clin Psychopharmacol. 2015;35(3):242-9.

8. McElroy SL, Guerdjikova AI, Blom TJ, et al. A placebo-controlled pilot study of the novel opioid receptor antagonist ALKS33 in binge eating disorder. Int J Eat Disord. 2013;46(3):239-45.

9. O'Malley SS, Todtenkopf MS, Du Y, Ehrich E, Silverman BL. Effects of the opioid system modulator, samidorphan, on measures of alcohol consumption and patient-reported outcomes in adults with alcohol dependence. Alcohol Clin Exp Res. 2018;42(10):2011-21.

10. Potkin S, Silverman B, Simmons A, Jiang Y, DiPetrillo L, McDonnell D. A phase 3 study to determine the antipsychotic efficacy and safety of ALKS 3831 in adult patients with acute exacerbation of schizophrenia. Poster presented at the American Psychiatric Association (APA) Annual Meeting; 5-9 May 2018; New York, NY.

11. Silverman BL, Martin W, Memisoglu A, DiPetrillo L, Correll CU, Kane JM. A randomized, double-blind, placebo-controlled proof of concept study to evaluate samidorphan in the prevention of olanzapine-induced weight gain in healthy volunteers. Schizophr Res. 2018;195:245-51.

12. Oleson E DD, Turncliff RZ. In vitro and in vivo metabolic profiling of samidorphan, a novel opioid receptor modulator. Poster presented at the FIP pharmaceutical sciences 2010 World Congress; 14-18 Nov 2010; New Orleans, LA.

13. Gonzalez JP, Brogden RN. Naltrexone. A review of its pharmacodynamic and pharmacokinetic properties and therapeutic efficacy in the management of opioid dependence. Drugs. 1988;35(3):192-213.

14. Smith K, Hopp M, Mundin G, et al. Low absolute bioavailability of oral naloxone in healthy subjects. Int J Clin Pharmacol Ther. 2012;50(5):360-7.

15. Sato M, Narukawa M. Factors affecting intrasubject variability of PK exposure: absolute oral bioavailability and acidic nature of drugs. Int J Clin Pharmacol Ther. 2015;53(11):955-62.

16. Trescot AM, Datta S, Lee M, Hansen H. Opioid pharmacology. Pain Phys. 2008;11(2 Suppl):S133-53.

17. Welling PG. Effects of food on drug absorption. Annu Rev Nutr. 1996;16:383-415.

18. Winstanley PA, Orme ML. The effects of food on drug bioavailability. Br J Clin Pharmacol. 1989;28(6):621-8.

19. Chow SC. Bioavailability and bioequivalence in drug development. Wiley Interdiscip Rev Comput Stat. 2014;6(4):304-12.

20. Koren G, Nordeng H, MacLeod S. Gender differences in drug bioequivalence: time to rethink practices. Clin Pharmacol Ther. 2013;93(3):260-2.

21. Harris DS, Jones RT, Welm S, Upton RA, Lin E, Mendelson J. Buprenorphine and naloxone co-administration in opiate-dependent patients stabilized on sublingual buprenorphine. Drug Alcohol Depend. 2000;61(1):85-94.

22. Weinberg DS, Inturrisi CE, Reidenberg B, et al. Sublingual absorption of selected opioid analgesics. Clin Pharmacol Ther. 1988;44(3):335-42.

23. Johnson FK, Stark JG, Bieberdorf FA, Stauffer J. Relative oral bioavailability of morphine and naltrexone derived from crushed morphine sulfate and naltrexone hydrochloride extended-release capsules versus intact product and versus naltrexone solution: a single-dose, randomized-sequence, open-label, three-way crossover trial in healthy volunteers. Clin Ther. 2010;32(6):1149-64.

24. McCann DJ. Potential of buprenorphine/naltrexone in treating polydrug addiction and co-occurring psychiatric disorders. Clin Pharmacol Ther. 2008;83(4):627-30.

25. Sgro MP, Modlin DL, Deaver DR, Kallman MJ, Todtenkopf MS. Evaluation of samidorphan, a mu-opioid antagonist, in a drug discrimination assay in rats. Drug Dev Res. 2018;79(5):234-8.

26. Pathak S, Vince B, Kelsh D, et al. Abuse potential of samidorphan: a phase I, oxycodone-, pentazocine-, naltrexone- and placebo-controlled study. J Clin Pharmacol. 2019;59(2):218-28.

27. Bidlack JM, Knapp BI, Deaver DR, et al. In vitro pharmacological characterization of buprenorphine, samidorphan, and combinations being developed as an adjunctive treatment of major depressive disorder. J Pharmacol Exp Ther. 2018;367(2):267-81. 